\title{
Prevalence of heart failure in the spanish general population aged over 45 years. the PRICE study
}

\author{
Manuel Anguita Sánchez, María G. Crespo Leiro, Eduardo de Teresa Galván, Manuel \\ Jiménez Navarro, Luis Alonso-Pulpón, Javier Muñiz García, on behalf of the PRICE \\ study investigators
}

\begin{abstract}
Introduction and objectives. Congestive heart failure is associated with substantial morbidity and mortality and both its incidence and prevalence are high. Nevertheless, comprehensive data on this condition in Spain are lacking. The aim of this study was to determine the prevalence of congestive heart failure in Spain.

Methods. A demographic study which involved the participation of 15 healthcare centers throughout Spain was carried out. In each health area, a random sample was taken of the population aged 45 years or more. These individuals were examined by their primary care physicians, who made their diagnoses using Framingham criteria. Individuals who satisfied criteria for congestive heart failure were referred to a cardiologist for confirmation of the diagnosis and for echocardiography.

Results. Overall, 1776 individuals were evaluated. Their mean age was $64 \pm 12$ years (range, $45-100$ years) and $44 \%$ were male. Of these, 242 were referred to a cardiologist. The weighted prevalence of congestive heart failure was $6.8 \%$ (95\% confidence interval [CI] 4-8.7). The prevalence was similar in men $(6.5 \%, 95 \%$ CI $4.7-8.4)$ and women (7\%, 95\% CI 4.4-9.6). When analyzed by age, the prevalence was $1.3 \%(0.4 \%-2.1 \%)$ in those aged $45-54$ years, $5.5 \%$ $(2.4 \%-8.5 \%)$ in those aged 55-64 years, $8 \%(4.2 \%-11.8 \%)$ in those aged $65-74$ years, and $16.1 \%(11 \%-21.1 \%)$ in those aged over 74 years.

Conclusions. Prevalence of congestive heart failure in Spain is high, at about 7\%-8\%. The prevalence was similar in males and females, and appeared to increase with age.
\end{abstract}

\section{Resumen}

Introducción y objetivos. La insuficiencia cardiaca congestiva (ICC) tiene elevadas incidencia, morbilidad y mortalidad y una gran prevalencia. Sin embargo, no hay datos directos sobre este aspecto en nuestro país. El objetivo de nuestro estudio es evaluar la prevalencia de ICC en España.

Métodos. Se diseñó un estudio poblacional en el que participaron 15 centros repartidos por toda España. Se seleccionó de forma aleatoria una muestra de la población de 45 o más años de edad atendida en cada área de salud, que fue estudiada por sus médicos de atención primaria. Se utilizaron los criterios de Framingham para el diagnóstico. Las personas con criterios de ICC fueron remitidas a una consulta de cardiología para confirmación diagnóstica y realización de ecocardiograma.

Resultados. Se evaluó a 1.776 personas, con una media \pm desviación estándar (intervalo) de edad de $64 \pm 12$ (45-100) años; eran varones el $44 \%$. Se remitió a cardiología a 242 pacientes. La prevalencia ponderada de ICC fue del 6,8\% (intervalo de confianza [IC] del 95\%, 4\%-8,7). La prevalencia fue similar en varones $(6,5 \%$; IC del 95\%, 4,7-8,4) y en mujeres (7\%; IC del 95\%, 4,4-9,6). Por edades, la prevalencia fue del 1,3\% (0,4\%-2,1\%) entre los 45 y 54 años; el $5,5 \%(2,4 \%-8,5 \%)$ entre 55 y 64 años; el $8 \%(4,2 \%-11,8 \%)$ entre 65 y 74 años, y el 16,1\% (11\%-21,1\%) en personas de 75 o más años.

Conclusiones. La prevalencia de ICC en España es alta, en torno a un 7-8\%. La prevalencia es similar en varones y mujeres, y parece aumentar con la edad.

Key words: Heart failure; Prevalence; Epidemiology

Palabras clave: Insuficiencia cardiaca; Prevalencia; Epidemiología

Abbreviations: CHF, congestive heart failure; PRICE, estudio de prevalencia de insuficiencia cardiaca en España (prevalence of heart failure in Spain study) 


\section{Introduction}

Congestive heart failure (CHF) is becoming one of the main public health problems in developed countries. It is the cause of significant morbi-mortality in the general population and its incidence and prevalence are increasing due to the ageing of the population, improvements in health care, and improved survival in those with chronic diseases. The situation is exacerbated by the fact that CHF is the final stage of many heart diseases which have also seen significant improvements in survival. ${ }^{1,2}$ Although treatment and disease course for many heart conditions have improved, morbi-mortality in CHF has not decreased significantly. This is likely due to the fact that the CHF population are older and have higher rates of comorbidity. ${ }^{3,4}$ The increase in morbidity is reflected in increased hospital admissions, with CHF being the main cause of medical hospital admissions in patients over 65 years of age. ${ }^{4,5}$ On the other hand, ageadjusted mortality rates have decreased slightly in Spain., ${ }^{4,5}$

Although in many developed countries CHF appears to have become more prevalent in recent years, 5,6 studies of prevalence are usually not carried out at the national level. In Spain, the only population-level study to date was performed in Asturias over 10 years ago (in 1996). The results indicated a prevalence of $5 \%$ in the population aged 40 years or over. ${ }^{7}$ The prevalence of CHF in Spain is likely to have increased since then, due to the factors mentioned above. The present paper presents the results of the PRICE (Prevalencia de Insuficiencia Cardiaca en España, [Heart Failure Prevalence Study in Spain]) study. The study objective was to evaluate the prevalence of CHF in the general population aged 45 years or over in Spain.

\section{Methods}

The PRICE study was sponsored by the Heart Failure, Heart Transplant, and Alternative Treatment Section of the Spanish Society of Cardiology, and made use of the CHF units that participated in the BADAPIC (Base de Datos en Pacientes con Insuficiencia Cardíaca [Patients with Heart Failure Database]) registry. ${ }^{8}$ The 53 hospitals collaborating on the registry were initially sent an invitation to participate in the study.

The invitation included a brief survey to determine whether centers met certain requirements for inclusion in the study. These included having access and fluid communications with the corresponding primary care network as well as having capacity for the extra consultations and echocardiograms required by the study. Furthermore, all primary care centers in the corresponding health care area were required to provide a list of the entire population covered by the area, stratified by age and sex. Of the 53 centers contacted, 22 confirmed they would be able to comply with requirements. A total of 15 hospitals and the 55 health care centers corresponding to the same health care areas were included in the study (see Appendix): 3 in Asturias; 2 in Andalucía, Aragón, País Vasco, and Galicia; and 1 in Castilla-La Mancha, Murcia, Valencia, and Cantabria. Fieldwork was carried out in 2004 and 2005.

\section{Sampling Procedure}

Each hospital was required to include a given number of individuals aged $\geq 45$. Individuals included were distributed between the participating centers in the health area and were selected by simple random sampling from the center's population register of individuals aged $\geq 45$ years. A total of 2703 individuals were invited to participate through a letter from their primary care physician which described the study objectives and procedures.

\section{Diagnostic Criteria and Clinical Examinations}

All participants were examined by their primary care physician to determine whether CHF was present. The modified Framingham criteria were used to decide on the presence of CHF (Table 1). A diagnosis of heart failure was assigned when there was a previous diagnosis of CHF confirmed after hospitalization or when 2 major criteria or 1 major and 2 minor criteria were present on examination. The clinician visit included assessment of the prior history of heart failure and cardiovascular risk factors in the medical record, a physical examination, an electrocardiogram, and a chest x-ray. Participants with a diagnosis of heart failure or with uncertain diagnosis were referred to the hospital for examination by a cardiologist. The cardiologist repeated the physical examination and evaluated the results of the ECG and chest X-ray. A Doppler echocardiogram was also performed. A final diagnosis of CHF was established when there were positive Framingham criteria and significant organic or functional anomalies on the Doppler echocardiogram (ejection fraction $<45 \%$; diastolic dysfunction with abnormal relaxation pattern, 
distensibility or pseudonormal pattern; a minimum of moderate mitral or aortic valve damage, or left ventricular hypertrophy). The cardiologist also established CHF etiology, functional capacity, and type of CHF (depressed systolic function was defined as left ventricular ejection fraction $<45 \%$, and preserved systolic function as ejection fraction $\geq 45 \%$ ). In order to analyze the reliability of the primary care diagnosis and the agreement between specialists and primary care physicians, a random sub-sample of 5\% of participants without clinical indications of CHF was included at the primary care visit and referred for assessment by a cardiologist. The hospital evaluation included a Doppler echocardiogram.

Table 1. Framingham Criteria (Modified) for the Diagnosis of Left Heart Failure

$\begin{array}{ll}\text { Major criteria } & \text { Paroxysmal nocturnal dyspnea } \\ \text { Rales } \\ \text { S3 gallop } \\ \text { Radiographic cardiomegaly } \\ \text { Radiological signs of pulmonary edema } \\ \text { Dyspnea on ordinary exertion } \\ \text { Nocturnal cough } \\ \text { Tachycardia }>120 \text { beats/min } \\ \text { Radiological pleural effusion } \\ \text { Weight loss }>4.5 \mathrm{~kg} \text { in } 5 \text { days in response to diuretic treatment }\end{array}$

\section{Statistical Analysis}

To take into account limitations in sample selection, the sample was weighted to ensure that it was representative of the Spanish general population by age and sex. Weights were defined as the inverse of the probability of selection, assuming that the 15 hospitals selected were a random sample of all hospitals in Spain. It was also assumed that, while the prevalence of CHF may differ between different regions of Spain, these differences would not be related to the fact that a given hospital was part of the heart failure unit network. Likewise, we assumed that prevalence would be unrelated to the hospital's degree of access to primary care in the area. Finally, the weights assigned were readjusted so that the weighted sample had the same distribution by age group and sex as the population of Spain according to the 2001 census data. The weight assigned to each patient reflects the number of individuals in the Spanish population represented by that patient, taking into account age group and sex. ${ }^{9}$ The sum of all the weights is therefore equal to the size of the Spanish population aged 45 or over. Weighted prevalences for CHF were calculated for the population as a whole as well as for specific age groups and by gender.

Cohen's kappa statistic ${ }^{10}$ was used to estimate agreement between the primary care physician's and the cardiologist's assessment. Results are presented as the percent agreement. The cardiologist's diagnosis (which included the results of the Doppler echocardiogram) was considered the gold standard. ${ }^{11}$

Point estimates and 95\% confidence intervals (CI) are used to present the results. The stepwise sampling strategy was taken into account when calculating the degree of precision (the confidence intervals of the estimates).

\section{Results}

A total of 1776 individuals participated in the study (66\% of those invited to participate). Of these, 242 were evaluated both at primary care level and by a cardiologist. The distribution of the final sample of participants evaluated only in primary care and at both primary care and hospital level is shown in Table 2. Table 3 shows the characteristics of the study sample. The mean (standard deviation [SD]) of the population evaluated was 64 (12) years; $44.1 \%$ were male. Table 2 also shows the sample distribution by 10 year age splits and sex. Almost $64 \%$ of participants were living in towns or cities at the time of the study, compared to $36 \%$ who were living in rural locations. A total of $6.7 \%$ of the sample had a prior history of ischemic heart disease; $14.1 \%$ of diabetes; $29.5 \%$ of high blood pressure; $30.9 \%$ of hyperlipidemia; and $14.9 \%$ were current smokers. Of the overall sample, $4.1 \%$ had been diagnosed with heart failure during a previous hospital admission. 
Table 2. Distribution of Participants Attended in Primary Care and in Both Settings Means (Primary Care and Hospital) by Age Group and Sex

\begin{tabular}{|c|c|c|c|c|}
\hline \multicolumn{5}{|l|}{ Age, y } \\
\hline $45-54$ & Both & $14(14.3)$ & $31(21.5)$ & $45(18.6)$ \\
\hline \multirow[t]{2}{*}{$55-64$} & Primary care & $217(27.7)$ & $268(26.9)$ & $485(27.3)$ \\
\hline & Both & $32(32.7)$ & $29(20.1)$ & $61(25.2)$ \\
\hline $65-74$ & Both & $25(25.5)$ & $45(31.3)$ & $70(28.9)$ \\
\hline \multirow[t]{2}{*}{$>75$} & Primary care & $167(21.3)$ & $218(22)$ & 385 (21.7) \\
\hline & Both & $27(27.6)$ & $39(27.1)$ & $66(27.3)$ \\
\hline \multirow[t]{2}{*}{ Total } & Primary care & $783(44.1)$ & $993(55.9)$ & 1776 \\
\hline & Both & $98(40.5)$ & $144(59.5)$ & 242 \\
\hline
\end{tabular}

Table 3. Sample Characteristics $(n=1776)$

\begin{tabular}{lc}
\hline & $\%$ \\
\hline Resident in urban area & 63.9 \\
Educational level & \\
Primary & 73.5 \\
Middle & 22.5 \\
High & 4.1 \\
Personal antecedents & \\
Ischemic heart disease & 6.7 \\
Diabetes & 14.1 \\
Hyperlipidemia & 33.8 \\
High blood pressure & 30.9 \\
Obesity & 29.5 \\
Cigarette consumption & \\
Active smoker & 14.9 \\
Ex-smoker & 19.6 \\
Previous diagnosis of heart failure & 4.1 \\
\end{tabular}

The prevalence of CHF, by age group and sex, are shown in Table 4. In the overall sample, $6.8 \%$ (95\% CI, 4.9-8.7) met the study definition for CHF. No difference in prevalence rates was observed by sex $(6.5 \%$ in men compared to $7 \%$ in women), but there were differences by age group, with prevalence rising rapidly with age. In the 45 to 54 year-old age group, prevalence was $1.3 \%$, compared to $5.5 \%$ in the 55-64 year-old age group, $8 \%$ in the 65-74 year-old age group, and $16.1 \%$ in those aged 75 or over (Table 4). The increase with age was similar in men and women (Table 4). Of those with $\mathrm{CHF}, 52 \%$ had depressed systolic function (left ventricular fraction <45\%) and $48 \%$ had preserved systolic function (ejection fraction $\geq 45 \%$ ). 
Table 4. Weighted Prevalence by Age Group and Sex

\begin{tabular}{cccc}
\hline & Men & Women & \\
\hline & & & \\
Age, $\mathrm{y}$ & & & \\
$45-54$ & $1.3(\ldots-2.7)$ & $1.2(\ldots-2.6)$ & $1.3(0.4-2.1)$ \\
$55-64$ & $7.4(1.3-13.5)$ & $3.6(1-6.2)$ & $5.5(2.4-8.5)$ \\
$65-74$ & $7(2.5-11.6)$ & $8.8(4.1-13.4)$ & $8(4.2-11.8)$ \\
$>75$ & $15.6(9.4-21.8)$ & $7(4.4-9.6)$ & $16.1(11-21.1)$ \\
Overall & $6.5(4.7-8.4)$ & & $6.8(4.9-8.7)$ \\
& & & \\
\hline
\end{tabular}

Data are shown in percentages $(95 \%$ confidence interval).

There was $86 \%$ agreement between primary care physicians and cardiologists in terms of diagnosis. Agreement on specific criteria was $\geq 90 \%$, except for cardiomegaly (85.6\%) and dyspnea on exertion $(87.2 \%)$

\section{Discussion}

According to the results of our study, the prevalence of heart failure in Spain is high, at around $6.8 \%$ of the population aged 45 or over. The prevalence rate is similar in men and women and clearly increases with age, to $16 \%$ in men and women aged over 75 years. Prevalence is $8 \%$ in the $65-74$ age group, $5.5 \%$ in the 55-64 age group, and $1.3 \%$ in the $45-54$ age group. The overall prevalence found here $(6.8 \%)$ is slightly higher than that found by Cortina et $\mathrm{al}^{7}$ in Asturias 8 years earlier (5\%). In the earlier study, a total of 391 individuals were evaluated and the clinical examination was performed by cardiologists; in over $80 \%$ of cases, the examination included evaluation using Doppler echocardiogram. Our study, on the other hand, was based on assessment in primary care, which could lead to an underestimate of heart failure prevalence. Nevertheless, there was substantial agreement $(86 \%)$ between assessments made in primary care and those made by the cardiologist.

The prevalence rate for heart failure observed here represents a considerable increase from figures published over the last 10 years for western countries. ${ }^{5,6}$ Data from the Framingham study showed a prevalence for $\mathrm{CHF}$ of $1 \%$ in individuals over 40 years of age. ${ }^{12}$ Cleland et al ${ }^{13}$ also reported a prevalence of $1 \%$, with an additional $2 \%$ of patients showing signs and symptoms of CHF after an exhaustive exploration (giving a total of 3\%). In Minnesota, in the county of Olmsted, a prevalence of CHF of only $2.2 \%$ was recorded between 1997 and 2000. ${ }^{14}$ The prevalence of CHF doubles with every decade of age, ${ }^{7,13}$ a finding which was confirmed in our study and which might, to a large extent, explain the increase in prevalence in $\mathrm{CHF}$ over the last 10-20 years. Another contributing and related factor, is the improvement in treatments for CHF and the associated decrease in mortality, as indicated in recent studies from Europe ${ }^{3}$ and the United States. ${ }_{15}$ In Spain, mortality from CHF has also decreased recently, ${ }^{4,5}$ although it remains the third most important cardiovascular cause of death after ischemic heart disease and stroke, in men and women. It has been shown to be responsible for $15 \%$ of total cardiovascular mortality ( $11 \%$ in men and $19 \%$ in women). ${ }^{16}$

Data from some studies have confirmed the increase in the prevalence of CHF in recent years ${ }^{16,17}$ and

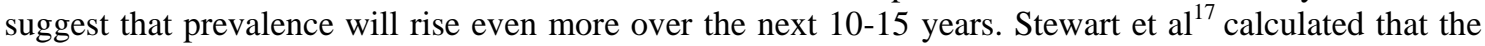
prevalence of CHF in Scotland will increase by $31 \%$ in men and 17\% in women between the year 2000 and 2020. Our results are in line with those forecasts, as well as with previous observations of a high prevalence of heart failure in women ${ }^{16}$ and in older age groups. ${ }^{17}$ As the average age of the population will almost certainly continue to rise and as life expectancy in women continues to exceed that of men, a heart failure "epidemic" appears increasingly likely, with the consequent need for greater treatment resources. Another interesting aspect of our data is that, of the total of heart failure cases found, ejection fraction was preserved in approximately half. This supports the results of recent studies in the United States. ${ }^{14}$

\section{Limitations}

Our study has some limitations which stem largely from the methodology used. The logistic complexity of a study of this type, which was performed throughout Spain, largely in primary care centers, and without financial remuneration for participating investigators, meant that the initial selection of centers was not randomized as it was considered essential to include investigators who would be committed to the study. This meant that large urban areas are under-represented and could, in addition, 
theoretically lead to a bias towards a higher number of CHF diagnoses. Nevertheless, confirmation of the diagnosis by cardiologists reduces that possibility. Agreement between primary care physicians and specialists, both in terms of the overall diagnosis of $\mathrm{CHF}$ as well as on specific clinical criteria, was very high ( $86 \%$ for the overall diagnosis). Another important source of bias could have been in the final selection of patients, though this was reduced by using random selection, and an acceptable degree of participation was also achieved. Finally, we have no information regarding prevalence in institutionalized patients and, in spite of the precautions taken and the high level of agreement between primary and specialist care, the possibility of under-diagnosis in primary care remains. Both aspects might lead to an underestimation of true prevalence rates.

\section{Conclusions}

Taking into account the limitations mentioned above, the results of our study indicate that the prevalence of CHF in Spain in the population aged 45 years or over is high, at almost $7 \%$. The prevalence rates are similar in men and women, and increase with age. These data, which are the first to be obtained in a nationwide study, can be used for future estimates of the magnitude of CHF in Spain and, with the aid of real local data, can be used to guide resource allocation for the management of the disease.

\section{Acknowledgements}

The authors wish to thank Dña. M. Isolina Santiago Perez for her advice on data analysis.

\section{References}

1. JG Cleland, A Khand, A Clark. The heart failure epidemic: exactly how big is it?. Eur Heart J, 22 (2001), pp. 623626.

2. J Segovia Cubero, L Alonso-Pulpon Rivera, R Peraira Moral, L Silva Melchor. Etiología y evaluación diagnóstica en la insuficiencia cardíaca. Rev Esp Cardiol, 57 (2004), pp. 250-259.

3. K MacIntyre, S Capewell, S Stewart, JW Chalmers, J Boyd, A Finlayson, et al. Evidence of improving prognosis in heart failure: trends in case fatality in 66547 patients hospitalized between 1986 and 1995. Circulation, 102 (2000), pp. 1126-1131.

4. F Rodriguez-Artalejo, P Guallar-Castillon, JR Banegas Banegas, J Del Rey Calero. Trends in hospitalization and mortality for heart failure in Spain, 1980-1993. Eur Heart J, 18 (1997), pp. 1771-1779.

5. F Rodríguez-Artalejo, JR Banegas, P Guallar-Castillón. Epidemiología de la insuficiencia cardíaca. Rev Esp Cardiol, 57 (2004), pp. 163-170.

6. JJ MacMurray, S Stewart. Heart failure: Epidemiology, etiology and prognosis of heart failure. Heart, 83 (2000), pp. 596-602.

7. A Cortina, J Reguero, E Segovia, JL Rodríguez-Lambert, R Cortina, JC Arias, et al. Prevalence of heart failure in Spain (a region in the north of Spain). Am J Cardiol, 87 (2001), pp. 1417-1419.

8. M Anguita, en representación de los autores del registro BADAPIC. Características clínicas, tratamiento y morbimortalidad a corto plazo en pacientes con insuficiencia cardíaca controlados en consultas específicas de insuficiencia cardíaca. Resultados del registro BADAPIC. Rev Esp Cardiol, 57 (2004), pp. 1159-1169.

9. LC Silva. Diseño razonado de muestras y captación de datos para la investigación sanitariaDíaz de Santos, Madrid (2000).

10. JR Landis, GG Koch. The measurement of observer agreement for categorical data. Biometrics, 33 (1977), pp. $159-174$.

11. T Greenhalgh. How to read a paper. Papers that report diagnostic or screening tests. BMJ, 315 (1997), pp. 540543.

12. WB Kannel, AJ Belanger. Epidemiology of heart failure. Am Heart J, 121 (1991), pp. 951-957.

13. JGF Cleland, A Khand, A Clarck. The heart failure epidemic: exactly how big is it?. Eur Heart J, 22 (2001), pp. 623-626.

14. MM Redfield, SJ Jacobsen, JCV Burnett, DW Mahoney, KR Bailey, RJ Rodeheffer. Burden of systolic and diastolic ventricular dysfunction in the community. JAMA, 289 (2003), pp. 194-202.

15. D Levy, S Kenchaiah, MG Larson, EJ Benjamín, MJ Kupka, KL Kalon, et al. Long term trends in the incidence of and survival with heart failure. N Engl J Med, 347 (2002), pp. 1397-1402.

16. TM Koelling, R Chen, RN Lubwama, GJ L'Italien, KA Eagle. The expanding national burden of heart failure in the United States: the influence of heart failure in woman. Am Heart J, 137 (2004), pp. 74-78. 17. S Stewart, K MacIntyre, S Capewell, JJV McMurray. Heart failure and the aging population: an increasing burden in the 21st century?. Heart, 89 (2003), pp. 49-53. 